\title{
Correction to: Reference microarchitectural values measured by HR-pQCT in a Franco-Swiss cohort of young adult women
}

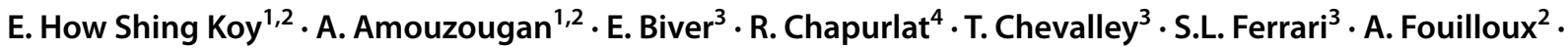 \\ H. Locrelle ${ }^{1,2} \cdot$ H. Marotte ${ }^{1,2} \cdot$ M. Normand ${ }^{2} \cdot$ R. Rizzoli ${ }^{3} \cdot$ L. Vico $^{2} \cdot$ T. Thomas $^{1,2}$ (D)
}

Published online: 8 November 2021

(C) International Osteoporosis Foundation and National Osteoporosis Foundation 2021

\section{Correction to: Osteoporos Int https://doi.org/10.1007/s00198-021-06193-x}

The first name and surname of the first author have been misabbreviated. It should be E. How Shing Koy instead of E. H. S. Koy.

The original article has been corrected.

Publisher's note Springer Nature remains neutral with regard to jurisdictional claims in published maps and institutional affiliations.

The original article can be found online at https://doi.org/10.1007/ s00198-021-06193-x

T. Thomas

thierry.thomas@chuse.fr

1 Department of Rheumatology, Hôpital Nord, CHU Saint-

Etienne, Saint-Etienne, France

2 INSERM U1059, Université de Lyon, Saint-Etienne, France

3 Service of Bone Diseases, Geneva University Hospitals and Faculty of Medicine, Geneva, Switzerland

4 INSERM U1033, Hôpital Edouard Herriot, HCL, Lyon, France 